Meta

Journal des traducteurs

Translators' Journal

\title{
Technical Translation in Japan
}

\section{William A. Lise}

Volume 33, numéro 1, mars 1988

Traduction et interprétation au Japon

Translation and Interpretation in Japan

URI : https://id.erudit.org/iderudit/003512ar

DOI : https://doi.org/10.7202/003512ar

Aller au sommaire du numéro

Éditeur(s)

Les Presses de l'Université de Montréal

\section{ISSN}

0026-0452 (imprimé)

1492-1421 (numérique)

Découvrir la revue

\section{Citer cet article}

Lise, W. A. (1988). Technical Translation in Japan. Meta, 33(1), 44-49.

https://doi.org/10.7202/003512ar d'utilisation que vous pouvez consulter en ligne.

https://apropos.erudit.org/fr/usagers/politique-dutilisation/ 


\section{TECHNICAL TRANSLATION IN JAPAN}

WilliaM A. LISE

Newtech, Tokyo, Japan

\section{INTRODUCTION}

With Japan's highly developed skill at manufacturing and selling hardware into overseas markets, translation of technical documentation, including sales materials relating to this hardware, plays a vital role in supporting Japan's export-based economy. Since exporting hardware (rather than software, such as ideas and culture) is Japan's strong suit, the focus of this report will be hardware- and technology-related translation. Also, since technical translation in Japan almost always means translation from Japanese into English (at least as one step in the overall process), this report will be chiefly limited to this sector, although most of the comments herein apply to translations to and from other languages in Japan as well.

\section{MARKET COMPOSITION}

The Japanese-to-English technical translation market in Japan is overwhelmingly dominated by customers requesting translation of product-related documentation, with work generated from the scientific/academic sector ranking a rather low second place. Since almost all of the work is generated by writers of Japanese manuscripts who want their manuscripts to be read and understood in a foreign-language market, the average customer is willing to pay much higher rates (by several times in many cases, it appears) than a non-Japanese customer who commissions work in Japan in order to find out what the writer of a Japanese manuscript has said.

One might expect that the huge companies which have become household words around the world would be generating the major portion of translation work in Japan. True, such corporate giants must surely play a major role. But, for every such company, there are dozens, perhaps hundreds, of companies that busily churn out hundreds of pages of Japanese manuscripts for translation every month. Many of these maintain their anonymity outside of Japan by virtue of OEM (original equipment manufacturer) agreements with exporters and overseas customers who mask the identity of these manufacturers with their own brand names. This core of exporting companies produces enough work to easily keep a large number of translators busy at the task of solving the problems of translating often superior technology into at least usable documentation for overseas markets. The results of these efforts can range in quality from totally useless to a level of quality that exceeds the original in terms of both organization and clarity. The obvious key to determining the quality of the end product is the availability of and willingness to use capable translators.

\section{TRANSLATORS IN JAPAN}

The translator, essentially the key to solving the myriad of translation problems in Japan, remains an elusive individual, defying any reliable definition or classification beyond information garnered from individual contacts with actual translators. 


\subsection{Who Are They?}

Although it would be difficult to argue against the basically sound position that translators should never translate into anything but their own native language (even with rewriting afterwards), a safe estimate would be that $95 \%$ of Japanese-to-English translation in Japan is done by Japanese, followed only sometimes by a review and rewriting process. This rewriting process is often erroneously termed proofreading, an indication of the serious lack of awareness of this problem. This sad state of affairs is characterized by the Japanese client who would not think of allowing a non-Japanese to translate into Japanese for revision by a native Japanese writer but shows no hesitation in allowing an unqualified non-Japanese rewriter with no knowledge of Japanese to rewrite material poorly translated into English or other languages by a Japanese.

Several reasons can be found for this bizarre situation. Probably the most influential is the huge amount of material which must be translated ; qualified (non-Japanese) translators are simply not plentiful enough. Another underlying reason is a widespread mistaken belief in the myth of the Japanese language as defying mastery by anyone who is not ethnically Japanese. A rational analysis of the problems involved would lead one, of course, to a different conclusion. Rationality, it must be remembered however, is a characteristic that the Japanese like to associate with foreigners and foreign thought processes.

\subsection{Background}

When we limit the discussion of qualifications to those of Japanese translators, we see a clearcut leaning towards liberal arts majors, with a rare smattering of ex-engineers who have made a career change to become either in-house or freelance translators. An advertisement for translators recently placed by a fairly well-known translation company requires that applicants (Japanese) have at least eight years experience in their field of specialization and this, one could assume based on the high number of liberal arts majors in this field, is aimed at an applicant from a non-technical background.

Quite a business has developed in Japan aimed at teaching translation and this business targets Japanese customers exclusively. Unfortunately, many of these schools attempt to teach English language skills they should already have before attempting translation into English, and a translation company looking for a capable translator cannot necessarily rely on a graduate of such an institution to be qualified.

The situation with regard to the non-Japanese translator population in Japan is quite different. Albeit, there are a number of Far East specialists in the non-Japanese translator community and, other conditions being equal, these translators would have the same trouble with technical translation as their liberal arts major Japanese counterparts. In general, however, we see non-Japanese translators coming from a wider range of fields, and it would be difficult to find a non-Japanese translator who acquired the Japanese language at a school for the specific purpose of someday becoming a translator. There are no formal institutions in Japan which specifically attempt to teach foreigners translation skills (the mythical non-learnability of the Japanese language will probably keep the situation this way) and the routes over which successful translators travel to gain proficiency are as numerous as the translators themselves. Some started as liberal arts majors and, after realizing the monetary rewards of translation and the hard fact that Japan simply does not export "liberal arts", were encouraged to acquire enough technical knowledge to succeed in technical translation. An acquaintance of the author, a German literature major from the UK, is a product of this last process and is one of the most capable and prolific technical translators the author has met. Still others came 
through the Japan studies route and cling to hopes of finding meaningful literary translation work while translating non-literary material to earn a living.

\subsection{Volume of Output : Translation in the Fast Lane}

Many translation companies in Japan expect that a translator be capable of producing at least 10 or 15 pages of finished work each day. It should be pointed out however, that a page in Japan is often nominally 200 words but can mean as few as 140 words, depending on the formating and word-counting conventions applied. Even with this loose definition, however, non-Japanese translators in Japan are often required to and do produce as many as $\mathbf{2 5}$ or $\mathbf{3 0}$ such pages of English daily. The Japanese translator, of course, could not be expected to reach this level when translating into a foreign language.

This volume of output does not necessarily imply that the work produced is usable as finished product ; even in the case of a native English-speaking translator, careful review and revision is almost always needed. In the case of the Japanese translator, this process is a much longer and costlier one and this is reflected in a much lower rate of payment when compared with native English-speaking translators.

One technique used by a small number of non-Japanese translators to increase their capacities is that of dictation for transcription into a word processor, followed by a step of revision to correct the problems which arise by virtue of the translation method itself, including misheard words and inconsistencies. Even with its intrinsic problems, however, this technique can achieve for the translator a dramatic increase in speed, while allowing the transcription typist to participate "on-line" in formating the manuscript for final presentation to the client.

\subsection{Translator Income}

An experienced non-Japanese translator working into his native language and supplied with a sufficient amount of work in a fairly narrow spread of fields (this is essential) should be able to earn $5000 \$$ monthly (calculated at Y $160=$ US $1 \$$ ). The translator earning at this level would never encounter a Japanese client earning anywhere near this amount and this can be the source of under-the-surface friction between users and providers of translations. More highly qualified translators with greater capacity for work and tolerance for tight scheduling can earn as much as double this amount or even more. The dynamics of the labor market for foreigners in Japan practically demands this level of income, since even non-qualified foreign English teachers in Japan (which means most such teachers in Japan) regularly earn two to three times the starting salary of the Japanese college graduate. The result is that, given a lower income than this for translation work, many translators would resort to English teaching.

Although the income figures for Japanese translators are, as would be expected, lower, they still compare very favorably with their counterparts working in nontranslation positions.

\section{APPROACHES TO THE TRANSLATION PROBLEM}

\subsection{In-House Translations}

Some Japanese manufacturers have taken the approach that in-house translators could best serve their needs. The author has asked some of these companies for their reasons and has come up with the following.

1. In-house translators can become more proficient at translation due to constant exposure to the same product line day after day. 
2. In-house translators are extremely economical compared to the approach of having outside translation companies provide such services.

3. The use of in-house personnel ensures the security of confidential material.

In talking with Japanese manufacturers, it is apparent that there is a widespread belief that only they could possibly be able to translate the manuscripts they produce. When probed as to why this is, many answer that they have been disappointed a number of times by translation companies that sold to them very effectively but were unable to produce acceptable translations.

Some Japanese manufacturers have hired foreign translators to work in-house, although many of these people are not allowed to translate because of the heavy rewriting load with which they are burdened. Because of the need to maintain what is often referred to as "balance" in salaries between employees, however, these manufacturers usually limit a captive foreigner's salary to the equivalent of a department chief's salary. Higher compensation than this usually results in emotional reactions that destroy the highly valued corporate $w a$, the harmony that is often credited with holding the company employees together in achieving corporate goals. However, this level of compensation is often not enough to lure foreigners into the highly restrictive work environment of the Japanese company, and most non-Japanese translators prefer to operate as freelances.

One particularly nasty problem created for the unfortunate rewriter in Japan is that of rewriting the English written by a Japanese in-house translator without the aid of the Japanese original. The author may feel that his English is close to being acceptable and merely needs "brushing up" or may merely be avoiding sending the Japanese manuscript along with the English to prevent being billed for retranslation, which in many cases is required. Often the translator will be told that there is no Japanese manuscript because the author was "thinking in English" during the writing process. Unfortunately, however, the rewriter is seldom sucessful at recreating this very doubtful thought process ; he is, after all, saddled with the limitation of only being able to think and reason in English as his native language, not as a foreign language.

\subsection{Outside Translation}

The great majority of translation work in Japan is done by "outsiders", either companies or individuals, with companies taking the lion's share of this market. This approach overcomes the major drawback of in-house translation, which is the inability to handle large volume. Obviously, this is a much costlier method, but the necessities of the market place dictate, in the author's opinion, that this will continue to be the most common approach for some time to come.

\section{TRANSLATION BUSINESS}

\subsection{The Requirements}

The most succinct method of characterizing the translation business in Japan is that of a sales and service oriented business. Translation companies (and, for that matter, individuals as well) are successful in getting business if they can :

1. be convincing in the context of sales done in the Japanese language (this is difficult for the Japanese and impossible for almost all the non-Japanese, including even most qualified translators)

2. be capable of producing a product satisfying the customer's requirements.

At first glance, these requirements seem rather obvious. Actual experience in the naarketplace, however, indicates to the contrary. Condition (1) keeps most individual translators (both foreign and Japanese) out of the marketplace, although a foreigner 
with excellent spoken Japanese and experience in sales (this is rare) will almost always be able to get to see a client, whereas his Japanese counterpart would have a difficult time getting by the receptionist. Condition (2) often means demands from the client for target language manuscripts which are understandable to the client, and this is not always conducive to effective writing in the target language.

\subsection{The Companies}

A quick study of the latest Tokyo classified telephone directory indicates a total of more than 600 listings under translation. Of these, the great majority are companies, but many are either individuals or have names indicating that they are translation offices but not legally incorporated as companies. The author has never seen statistics on this, but suspects that the average size of translation companies in Japan would be approximately four to five employees. This headcount sometimes includes personnel capable of translation but often does not and, in many cases, the person in charge is not a translator.

Many translation companies can be termed one-connection companies, since they were formed because of a personal connection or introduction which brought about a promise of translation work. One such company was, until recently, doing work for one of Japan's most prestigious copier companies and consisted of only one employee (the president), this person incapable of translation. The head of this company stated flatly that the relationship would always remain intact because of the long-standing personal connection. In fairness to other companies, however, it must be stated that many translation firms are run by working translators who are aware of the requirements both of the business and of the actual task of translation.

\section{RATES}

The issue of rates is a difficult one for two major reasons - scope of the translation work and method of counting for billing purposes.

\subsection{Where Pure Translation Ends}

A still-common attitude in Japan that translation is limited to the process of "coding" one set of symbols into another set of symbols completely ignores the actual requirements of the translation task. It is one thing for a qualified translator to produce a linguistically correct target language version of a Japanese manuscript. It is quite another for a translator having specialized knowledge and experience in the subject matter to apply these tools in producing a high-quality product that can often be superior to the source language. The rates which can and should be charged to customers for these two "levels" of translation are quite different.

\subsection{Counting}

While various schemes have been devised to count translated volume, commonly used ones include the "standard" page rate method, with a nominal page being approximately 200 words, and the word-count method with rates being applied per target language word.

An alternate approach (not a common one, it must be added) is to bill on the basis of source language volume, the justification for this being that an efficient rendering of a manuscript in the target language may very well be much shorter than the source text, especially if the author of the source was very verbose. 


\subsection{End-User Rate Range}

With the above stipulation with regard to scope and counting in mind, we see that technical translation from Japanese into English can be classified into several rate ranges.

\section{II $25 \$$ to $40 \$ /$ Page}

This rate range is usually applied to manuals and similar materials translated by Japanese and sometimes checked and rewritten by native English speakers. In this range, however, it is seldom possible to use highly qualified rewriters.

II $40 \$$ to $60 \$ /$ Page Minimum (Manuals) and $50 \$$ Minimum (catalogs and other sales materials)

In this price range, it is possible to enlist the services of native English speaking translators and copywriters. The rates to be expected for good catalog work can be as high as $100 \$$ a page or more, depending of course on the level of writing and afterservice required.

With regard to the above rates (and especially in the case of manual work), the actual page volume may only be 140 words or so, making a further calculation required to normalize the rates to some easily comparable scale.

\section{SUMMARY}

The above has been but a brief rambling stroll through the translation scene in Japan, based on the author's ten years in Japan in the position of both user and provider of translation services.

Very little has been written on this vital service industry in Japan and it is hoped that the comments herein will trigger more discussion and thought on how to better serve the needs of the industry.

Thanks go to my many colleagues who willingly or unwillingly subjected themselves to the brain-picking that made this report possible. 